Journal of Engineering and Applied Sciences 14 (12): 4290-4294, 2019

ISSN: 1816-949X

(C) Medwell Journals, 2019

\title{
Application of NDVI Data to Analyse the Effects of Sowing Methods and Seeding Rates on Soybean Crop Yield
}

\author{
${ }^{1,}{ }^{3}$ Boris Boiarskii, ${ }^{2}$ Hideo Hasegawa, ${ }^{3}$ Mikhail Sinegovskii, ${ }^{3}$ Valentina Sinegovskaia, ${ }^{3}$ Grigorii Chepelev \\ ${ }^{1}$ Graduate School of Science and Technology, \\ ${ }^{2}$ Institute of Science and Technology, Niigata University, Niigata, Japan \\ ${ }^{3}$ Federal State Budget Scientific Institution All-Russian Scientific Research Institute of Soybean, \\ Blagoveshchensk, Russia
}

\begin{abstract}
In soybean agriculture, it is very important to use specific seeding rates and sowing methods for particular varieties to ensure the production of high-quality seeds and rapid germination. At the All-Russian Scientific Research Institute of Soybean (ARSRIS), the effects of sowing methods and seeding rates on photosynthetic activity, crop yields and structure have been studied. We are currently introducing new methods of crop examination using UAV and multispectral camera technologies. As an experiment, these methods were used to show the application of UAV-derived data in crop analysis. The use of the Normalised Difference Vegetation Index (NDVI) in agriculture is beginning to develop rapidly and the need to introduce these technologies into the agriculture sphere is becoming urgent. Modern hardware such as multispectral cameras, makes remote analysis more informative and has a significantly expanded range of applications. The purpose of this research was to apply and demonstrate the relationship between obtained yield and NDVI values in an experiment with different seeding rates. Our results showed a relationship between yield and NDVI which will allow us to predict yield in future research on soybean analysis methods.
\end{abstract}

$\underline{\text { Key words: Amur Region, soybean, NDVI, breeding, seeding rate, sowing methods }}$

\section{INTRODUCTION}

The unique characteristic of soybean among all other field crops is the rich biochemical composition of its seeds. Soybean protein contents are the closest to animal proteins. Therefore, soybeans are considered one of the solutions to the protein deficiency problem in the world as a high-quality and low-cost food (Resnik, 1968).

The Amur Region in the Far East of Russia occupies a leading place in the production of agricultural products (Svetashova et al., 2017). Soybean is one of the most important and highly profitable crops in the Amur Region. The soil and climatic conditions of the region are favourable for soybean growth and development (Antonova and Sinegovskiy, 2016). Over 40\% of the total area of soybean crops in Russia is located in the Amur Region which has increased by $150 \%$ over the past 5 years and the average yield in the region has increased to 1.4 ton/ha (Yuan et al., 2018). To realize genetic potential yields and maximize the yield of high-quality seeds, it is necessary to investigate cultivation methods and develop varietal technologies that optimize the photosynthetic and seed productivity of crops.

Therefore, UAV technologies and index application are the most important tools in agriculture. The use of the Normalised Difference Vegetation Index (NDVI) in agriculture is beginning to develop rapidly and the need to introduce these technologies into the agriculture sphere is becoming urgent. Modern hardware such as multispectral cameras, makes remote analysis more informative and has a significantly expanded range of applications (Whelan and McBratney, 2012).

This study aimed to introduce the application of UAV-derived data to analyse soybean health as a rapid remote sensing tool for crop management. Recent studies showed that, depending on the sowing method and seeding rate, growth phase and development of new soybean varieties, the quantum yield of photosynthesis ranged from $0.362-0.782$ which contributed to a crop yield of 3.1-4.1 ton/ha. Therefore, the purpose of this research was to study the effects of sowing methods and seeding rates in new soybean varieties on growing conditions and crop yield using a UAV. We compared the obtained NDVI data with the yield to determine the best sowing conditions. The results showed that the application of UAV sensing is suitable for soybean analysis and future yield prediction.

\section{MATERIALS AND METHODS}

The objects of the research were the soybean varieties 'Kitrossa' and 'Kruzhevniza'. The research

Corresponding Author: Boris Boiarskii, Graduate School of Science and Technology, Niigata University, Niigata, Japan 
methods were field and laboratory experiments. Table 1 shows the sowing methods used which were selected on the basis of existing methodologies. The effects of sowing methods and seeding rates on photosynthetic activity, crop yield and structure have been studied at ARSRIS. These studies enable the development of agrotechnical methods of cultivation for each variety or group of varieties, taking into account the specific crop growth and development parameters and their relationship to growing conditions.

As a result of previous research, new knowledge has been obtained about the effects of sowing methods and seeding rates of new soybean varieties on production processes and seed quality (Tilba and Yushchenko, 2010). Therefore, year by year, the Research Institute needs to develop efficient sowing methods for new soybean varieties.

Table 2 shows the sowing scheme of the experiment. This scheme was applied for each variety. The field experiment was conducted in the experimental field for seed production and crop rotation at ARSRIS. The

\begin{tabular}{lc} 
Table 1: Experiment variations & \\
\hline Sowing method (row spacing, cm) & Seeding rate (thous. seeds/ha) \\
\hline 45 & 200 \\
& 400 \\
30 & 600 \\
& 200 \\
15 & 400 \\
& 600 \\
& 200 \\
\end{tabular}

sowing was replicated six times in random block plots. The total area of each experimental plot was $3.6 \mathrm{~m}^{2}$, registry $1.8 \mathrm{~m}^{2}$.

A DJ Matrice 100 UAV was used at a height of $10 \mathrm{~m}$ which gives high image quality and accurate data. We used the Micasense RedEdge camera which provides image capture in five spectra, for a wider analysis of the plants. Multispectral images were processed in the Pix4Dmapper Software which spent most of its time on post-processing because it analyses and links thousands of images into a single map. The flight was made on the experimental field on July 23, 2018. Images were taken and processed by the camera and an electronic field map was compiled which is shown in Fig. 1.

Table 2: Sowing scheme of the experiment

\begin{tabular}{llllll}
\hline & & & & & \\
\hline 49 & 50 & 51 & 52 & 53 & 54 \\
$30 / 600$ & $30 / 200$ & $30 / 400$ & $45 / 200$ & $45 / 600$ & $45 / 400$ \\
43 & 44 & 45 & 46 & 47 & 48 \\
$15 / 400$ & $15 / 600$ & $15 / 200$ & $30 / 400$ & $30 / 200$ & $30 / 600$ \\
37 & 38 & 39 & 40 & 41 & 42 \\
$45 / 200$ & $45 / 600$ & $45 / 400$ & $15 / 600$ & $15 / 400$ & $15 / 200$ \\
31 & 32 & 33 & 34 & 35 & 36 \\
$15 / 400$ & $15 / 200$ & $15 / 600$ & $30 / 400$ & $30 / 200$ & $30 / 600$ \\
25 & 26 & 27 & 28 & 29 & 30 \\
$45 / 600$ & $45 / 400$ & $45 / 200$ & $15 / 400$ & $15 / 600$ & $15 / 200$ \\
19 & 20 & 21 & 22 & 23 & 24 \\
$30 / 200$ & $30 / 600$ & $30 / 400$ & $45 / 600$ & $45 / 200$ & $45 / 400$ \\
13 & 14 & 15 & 16 & 17 & 18 \\
$15 / 200$ & $15 / 400$ & $15 / 600$ & $30 / 400$ & $30 / 200$ & $30 / 600$ \\
7 & 8 & 9 & 10 & 11 & 12 \\
$30 / 400$ & $30 / 600$ & $30 / 200$ & $45 / 200$ & $45 / 600$ & $45 / 400$ \\
1 & 2 & 3 & 4 & 5 & 6 \\
$45 / 600$ & $45 / 200$ & $45 / 400$ & $15 / 600$ & $15 / 200$ & $15 / 400$ \\
\hline & & & & &
\end{tabular}

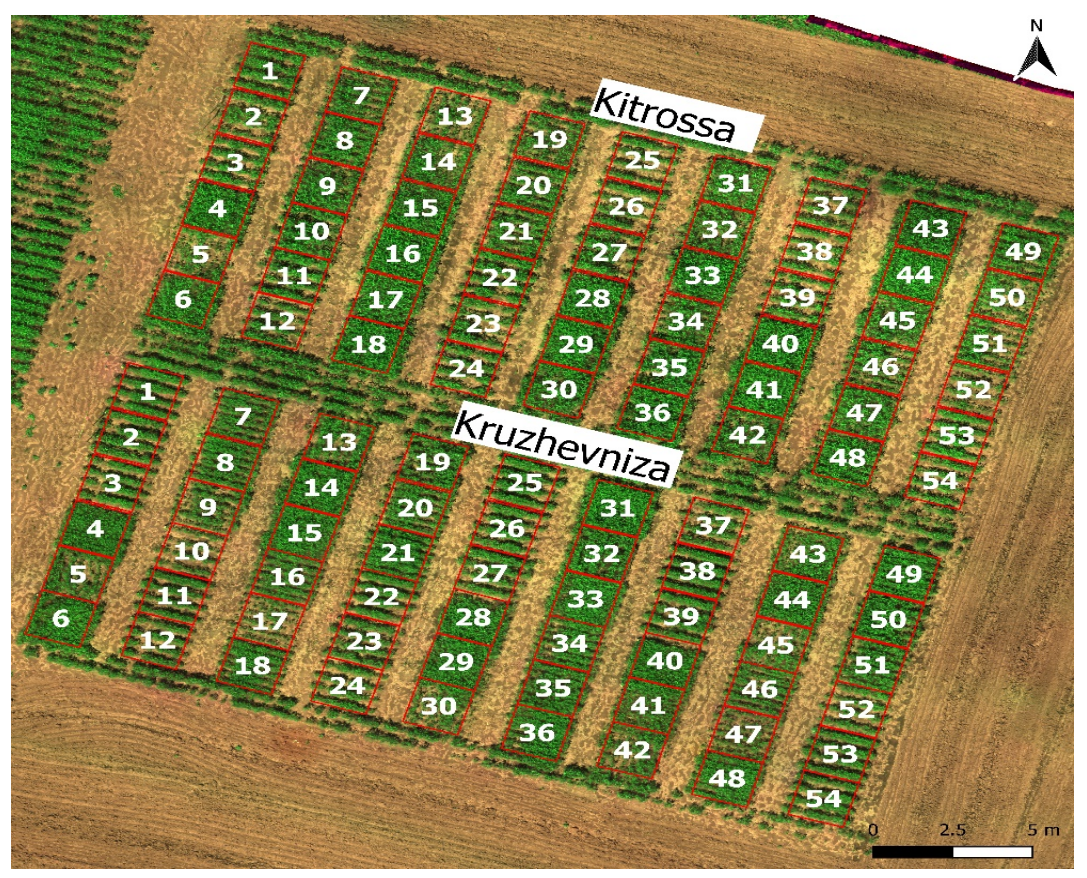

Fig. 1: UAV map of the study site 


\section{RESULTS AND DISCUSSION}

We analysed the NDVI and compared it with the productivity of the soybean varieties to determine the utility of this index in predicting soybean yield and building a mathematical prediction model in the future.

We analysed the images from the camera and made a multispectral image of the map. Based on the multispectral image, a layer with NDVI indexes was generated by the software. We then made a colour scheme map to visualize the status of the vegetation by NDVI values. The index was calculated from the reflectance of different wavelengths recorded in the metadata of the camera images.

The NDVI was represented with values from $0-1$ where the closer the index to 1 , the higher the amount of vegetation (Morikawa, 2014). Thus, NDVI is an index by which we can judge the development of the green activity of plants during a growing season (Tian et al., 2012). We used a Mesh method to calculate the index in which NDVI was calculated independently for each individual block plot. Additionally, the NDVI was calculated using average values. Figure 2 shows the post-processed map and calculated NDVI values. The NDVI values helped us to study the variability of chlorophyll fluorescence activities of new soybean varieties depending on the impact of the studied factors and to determine their relationship with productivity.

In phase V3 of plant development, the chlorophyll fluorescence index in the studied varieties varied from 428.8-652.6, depending on the seeding method and seeding rate. The highest rates, regardless of variety and seeding rate were observed in the flowering phase when soybeans were sown at a $30 \mathrm{~cm}$ spacing; for 'Kruzhevniza', the value was 692.3 and for 'Kitrossa', the value was 600.8 . Therefore, we can use the NDVI indicator during plant development to save time during in-depth analysis of plants and with large volumes. The ground and UAV tests did not differ in the analysis of vegetation activity.

The NDVI values, presented in Fig. 3, showed the vegetation activity in each test in which the highest rates were at $15 \mathrm{~cm}+400-600$ thous. seeds/ha and $30 \mathrm{~cm}+600$ thous. seeds/ha for both varieties.

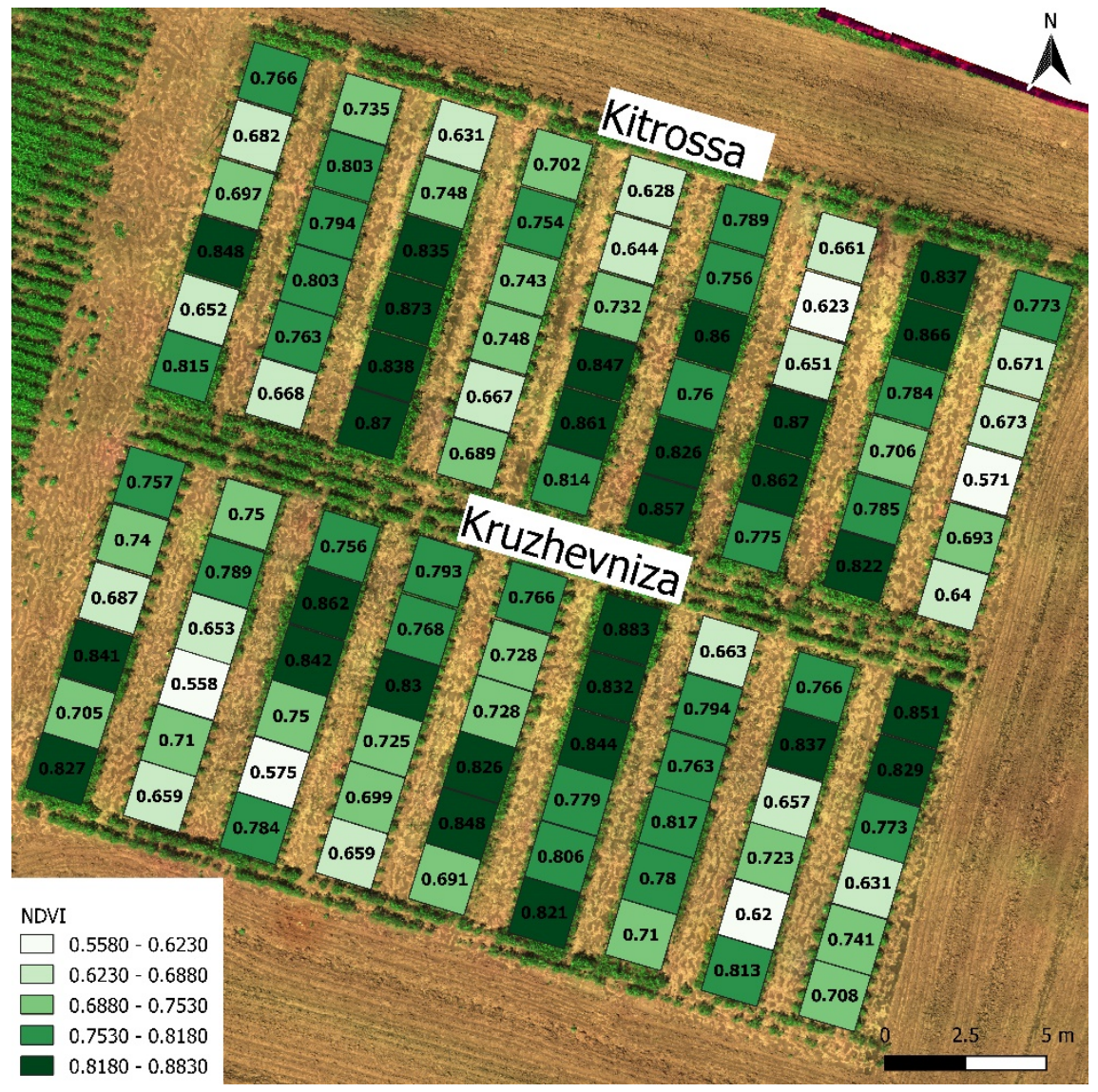

Fig. 2: NDVI classification map 

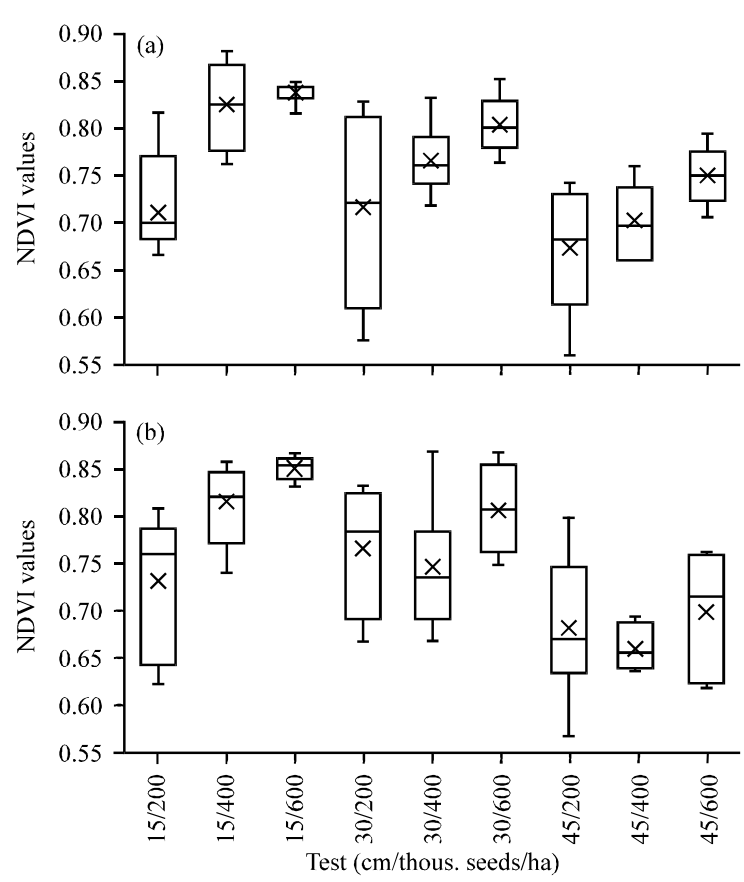

Fig. 3: NDVI values in each test; a) Soybean variety 'Kruzhevniza' and b) Soybean variety 'Kitrossa'
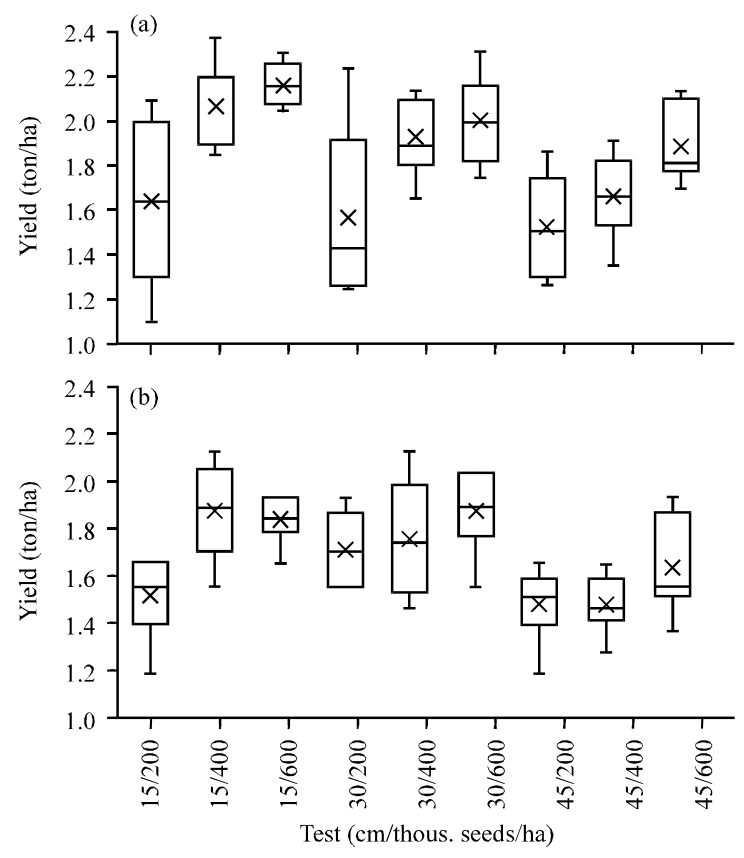

Fig. 4: Quantitative yield in each test; a) Soybean variety 'Kruzhevniza' and b) Soybean variety 'Kitrossa'

Figure 4 shows which planting conditions produced the highest quantitative yield. The data were collected from each experimental plot and processed for comparison with the greenness index for both varieties. The highest
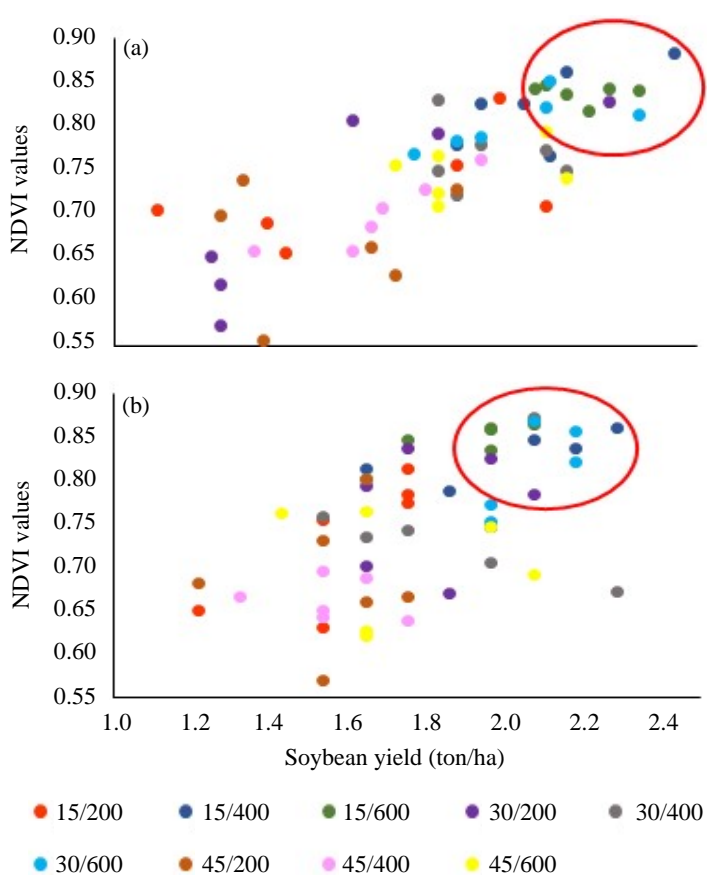

Fig. 5: Comparison of soybean yield and NDVI values; a) Soybean variety 'Kruzhevniza' and b) Soybean variety 'Kitrossa'

yield was achieved at seeding rates of $15 \mathrm{~cm}+400-600$ thous. seeds/ha and $30 \mathrm{~cm}+600$ thous. seeds/ha for both varieties. The ground test results showed that under the same conditions, maximum germination rate was reached (about 95\%) and the 1000-seed weight was $118 \mathrm{~g}$.

The relationship between NDVI values and yield in each experimental plot was found to be positive. Figure 5 shows that the maximum yield was achieved in plots with the highest NDVI values. The $15 \mathrm{~cm}+400$ thous. seeds/ha sowing conditions had a maximum index of 0.833 and yield of 2.44 ton/ha for the soybean variety 'Kruzhevniza'. Moreover, a minimum index of 0.575-0.653 and yield of 1.25-1.27 ton/ha were found under sowing conditions of $30 \mathrm{~cm}+200$ thous. seeds/ha. The high in the $15 \mathrm{~cm}+200$ thous. seeds/ha plot for 'Kruzhevniza' was due to the high density of germination with narrow sowing.

For soybean variety 'Kitrossa', the highest index and yield indicators were at $15 \mathrm{~cm}+400-600$ thous. seeds/ha and $30 \mathrm{~cm}+600$ thous. seeds/ha; the yield was 1.6-2.2 ton/ha and the index was $0.748-0.87$. The minimum rates were at $15 \mathrm{~cm}+200$ thous. seeds/ha and $45 \mathrm{~cm}+200-400$ thous. seeds/ha.

\section{CONCLUSION}

The results of this experiment demonstrate the utility of soybean crop assessment technologies using a UAV 
and multispectral camera. The experiment showed that the maximum yield was achieved in plots with the highest NDVI values. Thus, we proved that the NDVI could be considered as a tool for rapid crop analysis in the Amur Region. These technologies provide a novel way to help institutions and farmers analyse crops. Therefore, our goal is to bring these technologies to the Amur Region and the Russian Far East.

Analysis of the NDVI and its comparison with yield showed that in the future, this index could be used to predict the yield of soybean and build a mathematical model for predicting the yields of particular soybean varieties.

\section{ACKNOWLEDGEMENTS}

This study was made possible by the collaboration of researchers from Niigata University (Japan) and the All-Russian Scientific Research Institute of Soybean (Russia). We thank Robbie Lewis, MSc, from Edanz Group (www.edanzediting.com/ac) for editing a draft of this manuscript.

\section{REFERENCES}

Antonova, N.E. and M.O. Sinegovskiy, 2016. Cultivation of soybean in Amur Region in the context of global and national trends. Khabarovsk: Regionalistica, 3: 21-35.
Morikawa, R., 2014. Remote sensing tools for evaluating poverty alleviation projects: A case study in Tanzania. Procedia Eng., 78: 178-187.

Resnik, S.E., 1968. Nikolai Vavilov. Molodaya Gvardiya, Moscow, Russia, Pages: 336.

Svetashova, L.A., E.V. Klimkina and A.F. Klimkin, 2017. Current state of soybean production and evaluation of efficiency of technologies for its cultivation. Bull. Voronezh State Agrar. Univ., 3: 190-196.

Tian, X., W. Wenbin and Z. Qingbo, 2012. An estimation method of Winter wheat leaf area index based on hyperspectral data. Sci. Agric. Sin., 45: 2085-2092.

Tilba V.A. and B.I. Yushchenko, 2010. Problems of grain produce quality improvement in Amur River Region. Achiev. Sci. Technol. Agric., 11: 34-37.

Whelan, B.M. and A.B. McBratney, 2012. Downscaling for Site-Specific Crop Management Needs?. In: Digital Soil Assessments and Beyond, Minasny, B., B.P. Malone and A.B. McBratney (Eds.). Taylor and Francis, Abingdon, UK., pp: 353-356.

Yuan, M.S., V. Sinegovskaya and T. Han, 2018. Current status of the soybean industry and research in the Russian Federation. Soy Sci., 37: 1-7. 